\title{
PENGARUH SHALAT DHUHUR BERJAMAAH TERHADAP PERILAKU KEAGAMAAN SISWA DI KELAS VIII SMP MUHAMMADIYAH 8 BENJENG - GRESIK
}

\author{
Amanu, Hasan Basri \\ Fakultas Agama Islam Universitas Muhammadiyah Gresik \\ Amanu170295@gmail.com
}

\begin{abstract}
ABSTRAK
Penelitian ini bertujuan melakukan pengujian terhadap pengaruh pelaksanaan shalat dhuhur berjamaah terhadap perilaku keagamaan siswa SMP Muhammadiyah 8 BenjengGresik. Metode yang digunakan dalam penelitian ini adalah metode observasi, angket, wawancara, dan dokumentasi untuk mendapatkan data yang berhubungan dengan SMP Muhammadiyah 8 Benjeng-Gresik dan uji statistik menggunakan aplikasi SPSS dengan anlisis korelasi untuk mengetahui ada tidaknya pengaruh shalat dhuhur berjamaah terhadap perilaku keagamaan siswa SMP Muhammadiyah 8 Benjeng-Gresik tahun ajaran 2016-2017 yang berjumlah 123 siswa. Adapun sampelnya dari siswa sebanyak 32 siswa. Dari analisis tentang pengaruh shalat dhuhur berjamaah terhadap perilaku keagamaan siswa SMP Muhammadiyah 8 Benjeng-Gresik bahwa pelaksanaan shalat dhuhur siswa adalah dalam kategori sedang dengan persentase keterlaksanaan sebesar $59,4 \%$ dan perilaku keagamaan siswa adalah rendah sebesar 46,9\%. Adapun dari hasil statistik, penulis menarik kesimpulan bahwa terdapat pengaruh shalat dhuhur berjamaah terhadap perilaku keagamaan siswa SMP Muhammadiyah 8 Benjeng-Gresik dengan angka korelasi sebesar 0,463 yang tergolong dalam kategori cukup.
\end{abstract}

Kata kunci : Shalat Dhuhur, PerilakuKeagamaan 


\section{A. PENDAhuluan}

Pedidikan merupakan suatu upaya untuk mewariskan nilai, yang akan menjadi penolong dan penuntun untuk menjalani kehidupan dan sekaligus untuk memperbaiki nasib dan peradaban umat manusia. Pendidikan berintikan pada interaksi antara pendidik dan peserta didik dalam upaya membantu peserta didik untuk mencapai tujuan-tujuan pendidikan.

Shalat Jama'ah mempunyai nilai yang lebih, sama nilainya dengan shalat perorangan ditambah dua puluh tujuh derajat. Karena selain pahala yang berlipat ganda, shalat berjamaah juga akan menumbuhkan rasa kebersamaan yang kuat, seseorang tidak akan hidup tanpa adanya orang lain. Sehari saja jika tidak keluar rumah, tidak bertemu teman terasa dunia ini sepi. Begitu pula dengan shalat, shalatpun kalau dilakukan bersama teman dan orang lain (berjamaah) akan lebih mengasikkan dibanding dengan shalat sendirian, sehingga kita lebih semangat.

Dalam pendidikan di sekolah tidak hanya membutuhkan kecerdasan otak saja. Dengan banyaknya prestasi yang diraih oleh sebagian siswa, dapat menjadikan lengahnya guru dalam mendidik siswasiswa yang memiliki perilaku keagamaan yang baik. Apabila banyak moral atau akhlaq siswa yang kurang berkenan dengan melanggar peraturan-peraturan yang ada dalam sekolah. Bahkan ia tidak mempunyai aturan di luar sekolah. Dalam hal ini bagaimana usaha guru dapat menyelaraskan antara perilaku keagamaan dan kecerdasan spiritual. Sehingga menjadikan siswa-siswa yang diharapkan oleh guru dan orang tua.

Perilaku keagamaan adalah rangkaian perbuatan atau tindakan yang didasari oleh nilai-nilai agama ataupun dalam proses melaksanakan aturanaturan yang sudah ditentukan oleh agama dan meninggalkan segala yang dilarang oleh agama. Jelasnya, perilaku keagamaan itu tidak akan timbul tanpa adanya halhal yang menariknya. Pada umumnya penyebab perilaku keagamaan manusia itu merupakan campuran antara berbagai faktor baik lingkungan biologis, pskologis rohaniah, unsure fungsional, unsurr asli, fitrah ataupun karena petunjuk dari Tuhan.

Di SMP Muhammadiyah 8 Benjeng salah satunya sekolah yang menerapkan sholat dzuhur berjamaah. Seluruh siswasiswi diwajibkan untuk mengikuti peraturan yang telah dibuat oleh sekolah, dengan diadakannya kegiatan sholat dzuhur berjamaah diharapkan agar peserta didik agar mempunyai budi pekerti yang luhur, untuk diterapkan dalam kehidupan seharihari.

Sholat berjamaah di sekolah perlu dilatih sejak dini khususnya institusi sekolah terutama sekolah menengah, sholat berjamaah memiliki manfaat dan peranan yang sangat penting yakni sebagai 
pengontrol emosi dalam diri yang sedang puberitas ataupun masuk awal masa remaja awal dimana jiwanya masih labil karena sikap dan pendirian anak masih bersifat khayal berupa angan-angan bukan kenyataan.

Dalam proses pendidikan terdiri dari beberapa unsur yang berkaitan dengan pendidik atau guru, peserta didik, materi pelajaran, metode pengajaran, strategi pengajaran, penguasaan kelas, dan evaluasi. Yang mana setiap instansi atau lembaga mempunyai cara-cara tersendiri untuk meningkatkan kecerdasan anak didiknya. Sebagaimana aktifitas yang dilakukan di SMP Muhammadiyah 8 Benjeng, semua peserta didik diwajibkan untuk mengikuti sholat berjamaah secara rutin dan tertib. Dari pemaparan di atas, peneliti akan mengangkat sebuah judul "Pengaruh Sholat Dhuhur Berjamaah Terhadap Perilaku Keagamaan Siswa Di SMP Muhammadiyah 8 Benjeng".

Berdasarkan latar belakang yang telah dipaparkan di atas, maka permasalahan yang dapat dirumuskan oleh peneliti adalah: (1) bagaimana pelaksanaan sholat berjamaah siswa di SMP Muhammadiyah 8 Benjeng?, (2) bagaimana perilaku keagamaan siswa di SMP Muhammadiyah 8 Benjeng, (3) adakah pengaruh sholat berjamaah terhadap perilaku keagamaan siswa di SMP Muhammadiyah 8 Benjeng?

\section{B. TINJAUAN PUSTAKA}

1. Sholat Dhuhur Berjamaah

Menurut bahasa shalat adalah do'a. Kata "shalat" pada dasarnya berakar dari kata "Shalat" صلاة yang berasal dari kata Kata "shalat" menurut pengertian bahasa mengandung dua pengertaian, yaitu “ berdo'a” dan "bershalawat". Al-Qur'an menyebutkan shalat pada banyak ayat, tidak kurang dari 90 ayat, kata " shalat" mempunyai macammacam arti : "Do'a", “ Rahmat" dan "Istighfar" ( minta ampun).

Shalat dalam arti do'a di jelaskan dalam al-Qur'an surat At- Taubah, ayat 103 yang memerintahkan Nabi untuk mendo'akan bagi orang-orang yang membayar zakat harta benda mereka; sebab do'a Nabi membawa ketenangan hati mereka.

Kata jamaah artinya kumpul. Jadi pengertian "Sholat jamaah" menurut bahasa adalah sholat yang dikerjakan sama-sama lebih dari satu orang. Pengertian sholat berjamaah menurut pengertian syara " ialah sholat yang dikerjakan bersama-sama oleh dua orang atau lebih, salah seorang diantaranya bertindak sebagai imam (pemimpin yang harus diikuti) sedangkan yang lain disebut makmum, yang harus mengikuti imam.

Sebagian ulama' mengatakan bahwa hukum sholat berjama'ah itu adalah fardu 'ain, sebagian berpendapat bahwa sholat 
berjama'ah fardu khifayah, dan sebagian lagi berpendapat sunnah mu'akkad (sunat istimewa). Yang akhir inilah yang lebih layak, kecuali bagi sholat jum'at. Menurut kaidah persesuaian beberapa dalil dalam masalah ini, seperti yang telah disebutkan diatas, pengarang Nailul Autar berkata, "Pendapat yang seadil-adilnya dan lebih dekat kepada yang betul ialah sholat berjama'ah itu sunat muakkad."

Bagi laki-laki, sholat lima waktu berjama'ah di masjid lebih baik daripada sholat berjama'ah dirumah, kecuali sholat sunat, maka di rumah lebih baik. Bagi perempuan, sholat di rumah lebih baik karena itu lebih aman bagi mereka.

Sholat dhuhur berjamaah sangat berpengaruh terhadap perilaku keagamaan siswa. Sholat dhuhur berjamaah melatih siswa untuk lebih sabar, iktiar, dan tawakal kepada Allah SWT. dalam menghadapi dan melewati ujian dalam menuntut ilmu. Perilaku Keagamaan mempunyai peranan penting dalam kehidupan manusia dalam berbagai aspek kehidupan lebih khususnya lagi dunia pendidikan. Adanya keinginan yang ditimbulkan dari dalam diri baik perasaan bahagia, sedih, marah, semangat, rasa kesepian dan lain-lain.

\section{Perilaku Keagamaan}

Perilaku merupakan ekspresi dan manifestasi dari gejala-gejala hidup yang bersumber dari kemampuan kemampuan psikis yang berpusat adanya kebutuhan, seh ingga seolah perilaku manusia diarahkan untuk memenuhi kebutuhan hidupnya sebagai mahkluk individu, mahkluk sosial, dan mahkluk berketuhanan. Jadi perilaku mengandung sebuah tanggapan atau reaksi individu yang terwujud dalam gerakan (sikap) bukansaja badan atau ucapan.

Secara umum ada yang memaknai agama sebagai keyakinan atau sistem kepercayaan, serta merupakan seperangkat sistem kaidah. Sedangkan secara sosiologis, agama sekaligus menjadi sistem perhubungan dan interaksi sosial.

Jika disimpulkan pengertian di atas maka perilaku keagamaan adalah rangkaian perbuatan atau tindakan yang didasari oleh nilai-nilai agama ataupun dalam proses melaksanakan aturan-aturan yang sudah ditentukan oleh agama dan meninggalkan segala yang dilarang oleh agama. Jelasnya, perilaku keagamaan itu tidak akan timbul tanpa adanya hal-hal yang menariknya. Dan pada umumnya penyebab perilaku keagamaan manusia itu merupakan campuran antara berbagai faktor, lingkungan biologis, psikologis rohaniah, unsur fungsional, unsur asli, fitrah ataupun karna petunjuk dari Tuhan.

3. Pengaruh Sholat Berjamaah Terhadap Perilaku Keagamaan

Sholat dhuhur berjamaah sangat berpengaruh terhadap perilaku keagamaan 
siswa. Sholat dhuhur berjamaah melatih siswa untuk lebih sabar, iktiar, dan tawakal kepada Allah SWT. dalam menghadapi dan melewati ujian dalam menuntut ilmu. Perilaku Keagamaan mempunyai peranan penting dalam kehidupan manusia dalam berbagai aspek kehidupan lebih khususnya lagi dunia pendidikan. Adanya keinginan yang ditimbulkan dari dalam diri baik perasaan bahagia, sedih, marah, semangat, rasa kesepian dan lain-lain.

Bagi seseorang yang telah melakukan sholat berjama'ah dengan khusyuk akan menumbuhkan perilaku keberagaman yang baik, baik hubungan dengan Allah SWT maupun hubungan dengan sesama manusia. Kedudukan sholat berjama'ah dalam Islam merupakan wasilah paling ampuh dalam menghapus perbedaan status sosial antara kaum muslimin, menghilangkan sikap fanatik terhadap warna kulit, suku bangsa, dan nasab.

Dengan sholat berjama'ah akan berpengaruh terhadap perilaku keagaman baik yang bersifat hubungan dengan Allah dengan cara meningkatkan kualitas ibadahnya, maupun yang bersifat hubungan dengan sesama manusia yang berupa motivasi untuk senantiasa berperilaku baik menurut kadar ketaatannya.

Takbir sebagai pembuka sholat menunjukkan sebuah pengakuan dan sikap dasar dalam kehidupan seoarang Muslim hanya Allah SWT yang maha besar, sehingga menumbuhkan pengabdian, permohonan, dan penyandaran hidup hannya kepada Allah SWT semata. Gerakan sholat seperti ruku', I'tidal, sujud, dan tahiyat merupakan simbol penghormatan hakiki kepada Allah. Tatkala sujud, kepala kita disejajarkan dengan tanah. hal itu bermakna, di hadapan Allah manusia dan tanah sama-sama makhluk maka tidak pantas jika kita berlaku angkuh, gila hormat, dan sebagainya, sebab pujian dan penghormatan hakiki hanya diberikan kepada Allah SWT.

Sholat ditutup dengan salam, sambil menengok ke kanan dan ke kiri. Ketika menutup sholat itu kita mendoakan orang di sekitar kita agar diberi keselamatan dan keberkahan. Bacaan dan gerakan itu bermakna, seorang Muslim hendaknya menebar kemaslakhatan dan manfaat bagi orang lain, bukan menjadi "trouble maker" atau pembawa bencana dan kesulitan bagi orang lain.

Dengan demikian maka setiap peserta didik yang aktif mengikuti shalat berjamaah di masjid akan berpengaruh terhadap perilaku keagamaannya. Hal itu berarti semakin tekun mengikuti shalat jama'ah, akan semakin baik pula perilaku keagamaan siswa. 


\section{METODE PENELITIAN}

1. Identifikasi Variabel Penelitian

Varianbel X (variabel bebas atau variabel yang mempengaruhi) disini adalah sholat dhuhur berjamaah. Sholat dhuhur berjamaah merupakan salah satu bentuk latihan yang telah diberikan oleh pihak sekolah untuk melatih sholat berjamaah baik di rumah maupun di sekolah. Sholat dhuhur berjamaah adalah kegiatan yang diberlakukan untuk seluruh peserta didik dan tenaga pendidik serta kependidikan untuk memberikan contoh baik kepada peserta didiknya. Variabel Y (Variabel terikat atau variabel yang dipengaruhi) disini adalah perilaku keagamaan. Dalam hal ini perilaku atau sikap yang tercermin dalam keseharian peserta didik baik dalam hal menerima pelajaran, kemudian cara bertingkah laku terhadap guru, teman sejawat, dan kakak kelas.

\section{Lokasi Penelitian}

Penelitian ini dilakukan di SMP Muhammadiyah 8 Benjeng, Kabupaten Gresik. Alasan peneliti memilih tempat ini karena SMP ini sudah berdiri lama dan tergolong maju, jumlah siswa dan pengajar yang cukup banyak serta letaknya yang cukup strategis membuat peneliti lebih mudah untuk mengunjunginya sebagai tempat penelitian.

\section{Populasi dan Sampel}

Populasi dalam penelitian adalah seluruh siswa kelas VIII SMP Muhammadiyah 8 Benjeng, Kabupaten Gresik yaitu sejumlah 123 siswa. Sedangkan sampel penelitian kali ini peneliti hanya akan mengambil sampel kelas VIII dengan jumlah keseluruhan 32 siswa.

4. Instrumen Penelitian dan Teknik Pengumpulan Data

Instrumen penelitian yang digunakan dalam penelitian ini adalah metode angket dan dokumentasi. Anket diberikan kepada siswa secara langsung yang berisi beberapa pertanyaan yang sudah tersedia alternatif jawabannya, angket ini digunakan untuk memperoleh data tentang pengaruh sholat dhuhur berjamaah dan perilaku keagamaan. Sedangkan dokumentasi digunakan untuk memperoleh data dari keterangan siswa sebagai pelengkap hasil penelitian.

\section{Teknik Analisis Data}

Dalam penelitian ini menggunakan jenis penelitian Kuantitatif karena dalam mengolah data untuk menguji hipotesis dengan berbentuk angka atau teknik statistik.

Setelah mengetahui hasil angket sholat duhur berjamaah dan perilaku keagamaan siswa, maka untuk menguji adakah korelasi antar variabel dalam hipotesis dalam teknik statistik tersebut, ialah teknik Korelasi 
Product Moment dan menggunakan program SPSS (Statistical Product and Service Solutions) 16 for windows. Yang mana penulis dapat mengetahui korelasi antara sholat duhur terhadap perilaku keagamaan. Langkah penggunaan rumus korelasi sebagai berikut :

$$
r_{x y}=\frac{X-Y}{n}
$$

Keterangan :

$$
\begin{aligned}
& \mathrm{r}_{\mathrm{xy}}=\text { Nilai korelasi hitung yang dicari } \\
& \mathrm{X}=\text { Nilai variabel } \mathrm{X} \text { (sholat duhur } \\
& \quad \text { berjamaah) } \\
& \mathrm{Y}=\text { Nilai variabel } \mathrm{Y} \quad \text { (Perilaku } \\
& \text { Keagamaan) } \\
& \mathrm{N}=\text { Nilai subyek }
\end{aligned}
$$

Langkah-langkah selanjutnya sebagai berikut :

a. Menyiapkan nilai variabel $\mathrm{X}$ dan variabel Y.

b. Memasukkan kedalam rumus.

c. Membandingkan $r_{x y}$ hitung dengan $r_{x y}$ pada tabel statistik.

Setelah mengetahui nilai korelasi hitung yang dicari $\left(\mathrm{r}_{\mathrm{xy}}\right), \quad$ kemudian membandingkan antara $r_{x y}$ hitung dengan $\mathrm{r}_{\mathrm{xy}}$ tabel statistik, maka dapat digunakan untuk menguji hipotesis statistik atau hipotesis nol $\left(\mathrm{H}_{0}\right)$.

\section{HASIL PENELITIAN DAN PEMBAHASAN}

1. Pelaksanaan Shalat Dhuhur Berjamaah di SMP Muhammadiyah 8 BenjengGresik
Tingkat pelaksanaan shalat dhuhur siswa di SMP Muhammadiyah 8 Benjeng Gresik dapat dilihat berdasarkan angket sholat dhuhur berjamaah sebanyak 22 soal yang telah diisi oleh 32 siswa kelas VIII. Analisis data hasil angket pelaksanaan sholat dhuhur berjamaah diperoleh skor tertinggi adalah 66 dan nilai terendah adalah 46. Dengan menggolongkan data tersebut ke dalam 3 kelas, maka dapat dikategorikan variasi tinggi, sedang, rendah sebagai berikut :

\section{Tabel 1}

\section{Klasifikasi Jawaban angket tentang} Sholat Dhuhur Berjamaah

\begin{tabular}{|c|c|c|}
\hline Klasifikasi & $\begin{array}{c}\text { Jumlah } \\
\text { Jawaban } \\
\text { Responden }\end{array}$ & $\begin{array}{c}\text { Keterangan } \\
\text { Jawaban }\end{array}$ \\
\hline $46-52$ & 6 & Rendah \\
\hline $53-59$ & 19 & Sedang \\
\hline $60-66$ & 7 & Tinggi \\
\hline Total & $\mathbf{3 2}$ & \\
\hline
\end{tabular}

Skor pelaksanaan sholat dhuhur berjamaah siswa di Sekolah Menengah Pertama Muhammadiyah 8 BenjengGresik dianggap sedang, yakni antara 53-59 sebanyak 19 siswa dengan prosentase sebesar 59,4\%.

2. Perilaku Keagamaan Siswa di SMP Muhammadiyah 8 Benjeng-Gresik

Tingkat perilaku Keagamaan siswa di SMP Muhammadiyah 8 Benjeng Gresik dapat dilihat berdasarkan angket 
perilaku keagamaan. Analisis data hasil angket diperoleh skor tertinggi adalah 157 dan nilai terendah adalah 92 . Dengan menggolongkan data tersebut ke dalam 3 kelas, maka dapat diketahui interval kelasnya, yaitu :

\section{Tabel 2}

\section{Prosentase Jawaban tentang Perilaku}

Keagamaan Siswa

\begin{tabular}{|c|c|c|}
\hline $\begin{array}{c}\text { Keterangan } \\
\text { Jawaban }\end{array}$ & $\begin{array}{c}\text { Jumlah Jawaban } \\
\text { Responden }\end{array}$ & $\begin{array}{c}\text { Klasifik } \\
\text { asi }\end{array}$ \\
\hline Rendah & 15 & $92-114$ \\
\hline Sedang & 14 & $115-137$ \\
\hline Tinggi & 3 & $138-157$ \\
\hline Total & $\mathbf{3 2}$ & \\
\hline
\end{tabular}

Berdasarkan data tersebut menunjukkan bahwa siswa SMP Muhammadiyah 8 Benjeng-Gresik dalam perilaku keagamaan termasuk dalam kategori rendah sebesar 46,9\% sebanyak 15 siswa.

3. Pengaruh Pelaksanaan Shalat Dhuhur Berjamaah terhadap Perilaku Keagamaan Siswa di SMP Muhammadiyah 8

Hasil analisis korelasi menggunakan SPSS (Statistical Product and Service Solutions) 16 for windows didapatkan hasil 0,463. Korelasi sebesar 0,463 mempunyai maksud hubungan antara variabel shalat dhuhur dan perilaku keagamaan cukup. Sedangkan arah hubungan adalah positif karena nilai $\mathrm{r}$ positif, berarti semakin tinggi kegiatan sholat dzuhur berjamaah maka semakin baik perilaku keagamaannya. Korelasi kedua variabel bersifat signifikan karena angka signifikansi sebesar $0,008<0,01$.

Menguji hipotesis, dapat dilihat dari besarnya angka $t$ penelitian. Dari hasil perhitungan SPSS (Statistical Product and Service Solutions) 16 for windows diperoleh angka $\mathrm{t}$ penelitian sebesar 2,861 .

Hasil perhitungan diperoleh angka $\mathrm{t}$ penelitian sebesar 2,861>t tabel sebesar 1,697 sehingga Ho ditolak dan $\mathrm{Ha}$ diterima. Artinya, terdapat pengaruh positif antara pelaksanaan shalat duhur dan perilaku keagamaan siswa SMP Muhammadiyah 8 BenjengGresik.

\section{KESIMPULAN}

Berdasarkan hasil penelitian yang telah dilakukan, maka dapat diperoleh beberapa simpulan penelitian yaitu sebagai berikut: (1) Proses pelaksanaan shalat dhuhur berjamaah yang dilaksanakan di Sekolah Menengah Pertama Muhammadiyah 8 Benjeng-Gresik adalah, shalat dhuhur dilaksanakan pada saat menjelang jam istirahat kegiatan belajar mengajar atau pada saat memasuki waktu sholat dhuhur yang dilaksanakan secara berjama'ah, dan dipimpin oleh guru 
maupun Kepala Sekolah. Absensi sholat dhuhur berjamaah dilakukan sebelum sholat dilaksanakan. Adapun bagi siswa perempuan yang halangan atau haid, mereka berkumpul di ruang baca perpustakaan untuk membaca asmaul husna atau materi tentang kewanitaan dan dibimbing oleh ibu guru yang bertugas, (2) Perilaku keagamaan siswa SMP Muhammadiyah 8 Benjeng-Gresik termasuk dalam kategori rendah sebesar 46,9\% sebanyak 15 siswa, kategori sedang sebesar 43,8\% sebanyak 14 siswa, dan kategori tinggi sebesar 9,3\% sebanyak 3 siswa, (3) Pengaruh shalat dhuhur terhadap perilaku keagamaan siswa Sekolah Menengah Pertama Muhammadiyah 8 Benjeng-Gresik termasuk dalam kategori cukup. Hal ini ditunjukkan dengan hasil analisis menggunakan SPSS 16.0 for windows yang menghasilkan angka $\mathrm{t}$ penelitian sebesar 2,861>t tabel sebesar 1,697 sehingga Ho ditolak dan Ha diterima. Artinya, terdapat pengaruh positif antara pelaksanaan shalat dhuhur dan perilaku keagamaan siswa SMP Muhammadiyah 8 Benjeng-Gresik.

Peneliti juga menyampaikan beberapa saran yang diharapkan bermanfaat, khususnya bagi pihak Sekolah Menengah Pertama Muhammadiyah 8 Benjeng-Gresik guna meningkatkan kualitas pendidikan dan pengajarannya dalam meningkatkan perilaku keagamaan siswa, yaitu
Pelaksanaan shalat dhuhur yang sudah baik agar ditingkatkan lagi supaya lebih baik, sedangkan perilaku keagamaan yang sudah baik supaya perlu dipertahankan, (2) Kepala Sekolah memberikan instruksi kepada para guru untuk dapat mengerjakan shalat dhuhur berjamaah secara rutin bersama siswa. Karena dengan rutin mengerjakan shalat dhuhur, dapat memanfaatkan waktu untuk mendekatkan diri kepada Allah SWT sehingga tercipta kehidupan yang seimbang antara urusan duniawi dan ukhrowi.

\section{DAFTAR PUSTAKA}

Abdullah As-Sadlani Sholih bin Ghanim bin, terj. M. Nur Abrari, 2002. Shalat Berjama'ah Panduan Hukum, Adab, Hikmah, Sunnah dan Peringatan penting tentang pelaksanaan Shalat berjama'ah, Solo: Pustaka Arafah.

Abdusshomad KH Muhyiddin, 2010. Sholatlah Seperti Rasulullah Saw (Dalil Keshahihan Shalat ala ASWAJA) Surabaya: Khalista.

Agustian Ary Ginanjar, 2001. Emotional Spiritual Quotient, Jakarta: Penerbit Arga.

Anas Sudijono, 2011. Pengantar Statistik Pendidikan, Jakarta: Rajawali Press.

Aziz Alfinar, 2003. Psikologi Pendidikan. Jakarta: Dinas pendidikan.

HaryantoSentot, 2005. Psikologi Shalat, Yogyakarta:Mutiara Pustaka. 
M Mahful, 2003. Meninggalkan Shalat?

Batas Hukum dan Sanksinya, cet.IV, Surabaya: Pustaka Progresif.

Mansur, 2005, Mendidik Anak Sejak Dalam Kandungan, Yogyakarta: Mitra Pustaka.

Masyur Syekh Mustofa, 2002. Berjumpa Allah Lewat Shalat, Jakarta: Gema InsaniPress.

Moleong Lexy J.2008. Metodologi Penelitian Kuantitatif, Bandung: Remaja Rosdakarya.
Saifudin Ayip, 2002. Islam dan Pendidikan Seks Anak, Solo: CV. Pustaka Mantiq. Sukmadinata Nana Syaodih,1997, Pengembangan Kurikulum, Bandung: PT. Remaja Rosdakarya.

UU RI No. 2 Tahun 1989, 1992. Tentang Sistem Pendidikan Nasional, Semarang: Aneka Ilmu.

Yusuf Syamsu, 2005. Psikologi Perkembangan Anak dan Remaja, Bandung: PT Remaja Rosdakarya.

Zuhairini, dkk., 1992. Filsafat Pendidikan Islam, Jakarta: Bumi Aksara. 